\title{
Preparation and Characterization of Green Porous Palm Shell Based Activated Carbon by Two Step Chemical Activation Using KOH
}

\author{
Abdurrahman Garba ${ }^{1, a}$, Hatijah Basri ${ }^{1, b^{*}}$ and Noor Shawal Nasri ${ }^{2, c}$ \\ ${ }^{1}$ Faculty of Science, Technology and Human Development. University Tun Hussein Onn Malaysia, \\ 86400 Parit Raja, Batu Pahat. Johor. \\ ${ }^{2}$ Sustainable Waste-to-Wealth Unit, Gas Technology Centre, Faculty of Petroleum \& Renewable \\ Energy Engineering, Universiti Teknologi Malaysia, 81310 UTM Johor, Johor, Malaysia . \\ aagarba2008@yahoo.com, bhatijah@uthm.edu.my*, cnoorshaw@petroleum.utm.my
}

Keywords: Adsorbent, Palm oil shell, chemical activation, Potassium hydroxide.

\begin{abstract}
The large quantity of agricultural waste materials that poses disposal challenge to our environment could be converted into useful products such as activated carbon (AC). Palm oil shell based porous $\mathrm{AC}$ was prepared by two step process using $\mathrm{KOH}$ as the chemical activant. Palm oil shell was carbonized at $800^{\circ} \mathrm{C}$ for 2 hours and activated using $\mathrm{CO}_{2}$ at same temperature for 1 hour which yield $23.27 \%$ fixed carbon. The AC was characterized by Langmuir surface area, BET surface area and pore volume of $410.7 \mathrm{~m}^{2} / \mathrm{g}, 350 \mathrm{~m}^{2} / \mathrm{g}$ and $0.2 \mathrm{~cm}^{3} / \mathrm{g}$ respectively, the FTIR analysis identified the presence of alkanes, carbonyls and hydroxyls as the main functional groups in the AC. Scanning electron microscopy images illustrates the gradual formation of pores from the precursor to the produced $\mathrm{AC}$ due to elimination of volatiles and contaminants in the material. However, the AC produced showed basic properties suitable for the removal of hydrophobic organic contaminants in water and wastewater.
\end{abstract}

\section{Introduction}

The presence of agricultural waste poses disposal challenge to areas with rapid growth of agriculture. However, Palm oil is the leading oil crop cultivated in the Southeast Asian countries for the production of cooking oil. Malaysia as example, is the largest exporter of palm oil in the world with over 5 million hectares of cultivated lands at an average production rate of 19.69 ton/hectare of fresh fruit bunch. About 2 million tons were generated annually as waste from such industry and among these waste are palm oil shell $[1,2]$. Converting such agricultural waste to useful materials such as adsorbents could solve their disposal problems. Commercially, the precursor materials used commonly for AC production is coal but due to its high cost, high demand and non-renewable nature made researchers to look for alternatives. Agricultural residues like palm oil shell are substitutes because they are readily available, cheap and possess suitable properties such as low inorganic materials content and high percentage composition of volatiles which helps to create the basic pore structure as they escape during carbonization processes [3].

The chemicals mostly used during activation are $\mathrm{K}_{2} \mathrm{CO}_{3}, \mathrm{LiOH}, \mathrm{ZnCl}_{2}, \mathrm{H}_{3} \mathrm{PO}_{4}, \mathrm{NaOH}$ and $\mathrm{KOH}$ [4-6]. Hence, the main aim of this study is to produce porous AC from palm oil shell using $\mathrm{KOH}$ as chemical activant with specific properties towards organic contaminants removal in water and wastewater.

\section{Experimental}

\section{Materials}

Palm oil shell was obtained from a local factory in Parit Raja, Johor, Malaysia. The palm shells were first washed with deionized water several times and then dried at $105^{\circ} \mathrm{C}$ for $24 \mathrm{hrs}$ in hot 
air oven. The palm shells were then crushed and separated using sieves and shaker into sizes between $0.6-1.18 \mathrm{~mm}$ which were used as starting material and levelled as raw palm shell (RPS).

Sample preparation

The precursor was chemically activated after carbonizing it initially from ambient temperature to carbonization temperature of $800^{\circ} \mathrm{C}$ under nitrogen flow of $150 \mathrm{~cm}^{3} / \mathrm{min}$ for $2 \mathrm{hrs}$ at $10^{\circ} \mathrm{C} / \mathrm{min}$ heating rate. The carbonized sample was then impregnated with $\mathrm{KOH}$ in the ratio 1:2 and the mixture was loaded into the reactor for subsequent heating to a temperature of $800^{\circ} \mathrm{C}$ for $1 \mathrm{hr}$ at $10^{\circ} \mathrm{C} / \mathrm{min}$ heating rate in the presence of nitrogen gas at $100 \mathrm{~cm}^{3} / \mathrm{min}$. Then it was heated for activation under $\mathrm{CO}_{2}$ flow of $150 \mathrm{~cm}^{3} / \mathrm{min}$ at $800^{\circ} \mathrm{C}\left(10^{\circ} \mathrm{C} / \mathrm{min}\right)$ for $1 \mathrm{hr}$. After activation, the samples were allowed to cool down to ambient temperature under nitrogen flow after which it was removed from the furnace. The carbon produced were then washed with $0.1 \mathrm{M} \mathrm{HCl}$, hot water and then by deionized water until the washing's $\mathrm{pH}$ were between 6-7 and it was dried in the oven at $105^{\circ} \mathrm{C}$ for $24 \mathrm{hrs}$. The AC produced was labelled as potassium carbonate treated carbon (PHAC) [7].

\section{Characterization}

The synthesized AC was characterized by BET surface area using Micromeritics ASAP 2020 for full isotherms analysis. Scanning electron microscopy (SEM) model JOEL JSM-7600F was carried out for both the raw precursor RPS and the activated carbon PHAC produced to study the pore development and surface morphology of the materials. The surface functionalities on the materials were analysed by Fourier transform Infrared Spectroscopy (FTIR) spectra recorded between $4000 \mathrm{~cm}^{-1}$ and $600 \mathrm{~cm}^{-1}$ at $4 \mathrm{~cm}^{-1}$ resolution and 16 scans $\mathrm{min}^{-1}$ using Parking Elmer Spectrum-100 model.

\section{Results and Discussion}

Surface area and pore volume

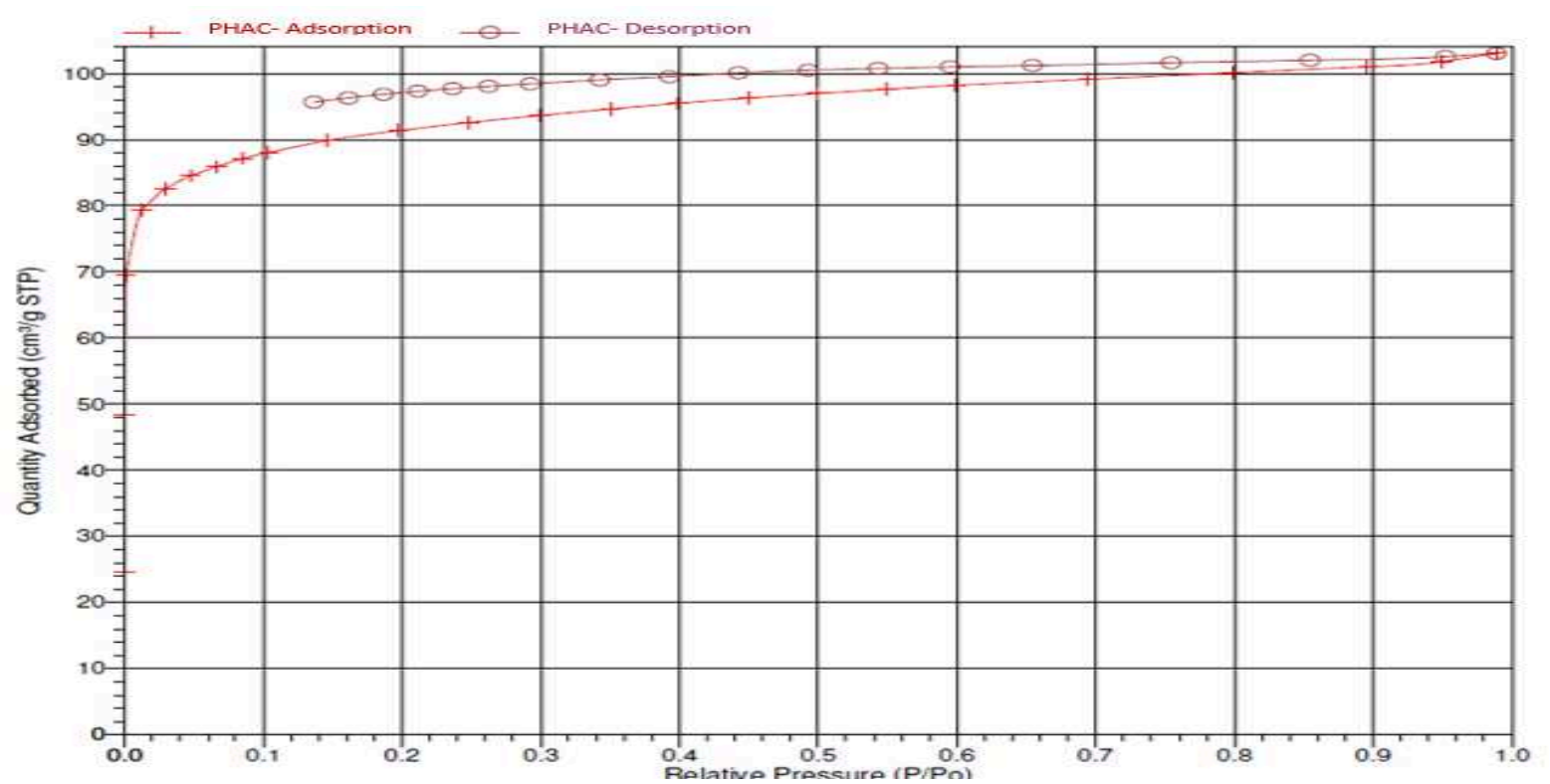

Figure. 1 Type I isotherm linear plot from $\mathrm{N}_{2}$ adsorption analysis of PHAC

The adsorptive capacity of activated carbon is its most important property which in general is proportional to the surface area $[2,8]$. The Langmuir surface area, BET surface area and pore volume of the activated carbon are $410.7 \mathrm{~m}^{2} / \mathrm{g}, 350 \mathrm{~m}^{2} / \mathrm{g}$ and $0.2 \mathrm{~cm}^{3} / \mathrm{g}$ respectively. The results compares with the studies obtained by Daud and Ali [9], where $260 \mathrm{~m}^{2} / \mathrm{g}$ from palm oil shell. They showed that, the specific surface area is achieved around $800^{\circ} \mathrm{C}$ and it decreases above $800-1000^{\circ} \mathrm{C}$. 
However, $\mathrm{KOH}$ is a good chemical activant around $800^{\circ} \mathrm{C}$ as increasing the carbonization temperature above $800^{\circ} \mathrm{C}$ increased the reaction rate between carbon and $\mathrm{KOH}$ which leads to increased carbon burn-off [10]. In fig. 2 above, it could be seen that the linear branch of the isotherms becomes curved which is no longer parallel to the pressure axis and a loop begin to appear which indicates a region of mesopores development [2].

Proximate analysis

Table 1. Proximate analysis of RPS and PHAC

\begin{tabular}{clccc}
\hline Sample & Moisture (\%) & Volatiles (\%) & Ash (\%) & Fixed carbon (\%) \\
RPS & 5.60 & 68.75 & 2.38 & 23.27 \\
PHAC & 4.50 & 7.40 & 7.50 & 80.60 \\
\hline
\end{tabular}

The proximate analysis of both raw precursor and the AC were presented in Table 1 with PHAC having relatively high percentage of fixed carbon $80.60 \%$ which is due to high removal of volatiles from the precursor as indicated by higher percentage of volatiles in it $(68.75 \%)$.

Elemental analysis

Table 2. Proximate and ultimate analysis showing percentage decomposition of palm oil shell in this study compared with other studies

\begin{tabular}{lcccc}
\hline $\begin{array}{l}\text { Proximate Analysis (\%) } \\
\text { Moisture }\end{array}$ & $\begin{array}{c}\text { Daud and Ali, 2004 } \\
7.96\end{array}$ & $\begin{array}{c}\text { Shin et al., 2014 } \\
4.0\end{array}$ & $\begin{array}{c}\text { Khan et al., 2014 } \\
9.61\end{array}$ & $\begin{array}{c}\text { This Study } \\
5.60\end{array}$ \\
Volatiles & 72.47 & 63.0 & 80.92 & 68.75 \\
Ash & 1.10 & 5.0 & 4.31 & 2.38 \\
Fixed Carbon & 18.70 & 27.0 & 14.67 & 23.27 \\
Ultimate Analysis (\%) & & & & \\
Carbon & 50.10 & 47.24 & 49.74 & 47.35 \\
Hydrogen & 6.85 & 4.87 & 5.68 & 5.40 \\
Nitrogen & 1.90 & 0.24 & 1.02 & 1.08 \\
Sulphur & - & 0.00 & 0.27 & 0.06 \\
Oxygen (by difference) & 41.15 & 47.65 & 43.36 & 46.11 \\
\hline
\end{tabular}

The precursor material has low ash content as seen on Table 2 which is considered as an added advantage for carbon synthesis. The fixed carbon content in this study $(23.27 \%)$ when compared with other studies, it is high as presented in Table $2[9,11,12]$. The high percentage composition of carbon in palm oil shell from the ultimate analysis $(47.35 \%)$ is an indication of a good precursor material for production of activated carbon [2]. 
SEM
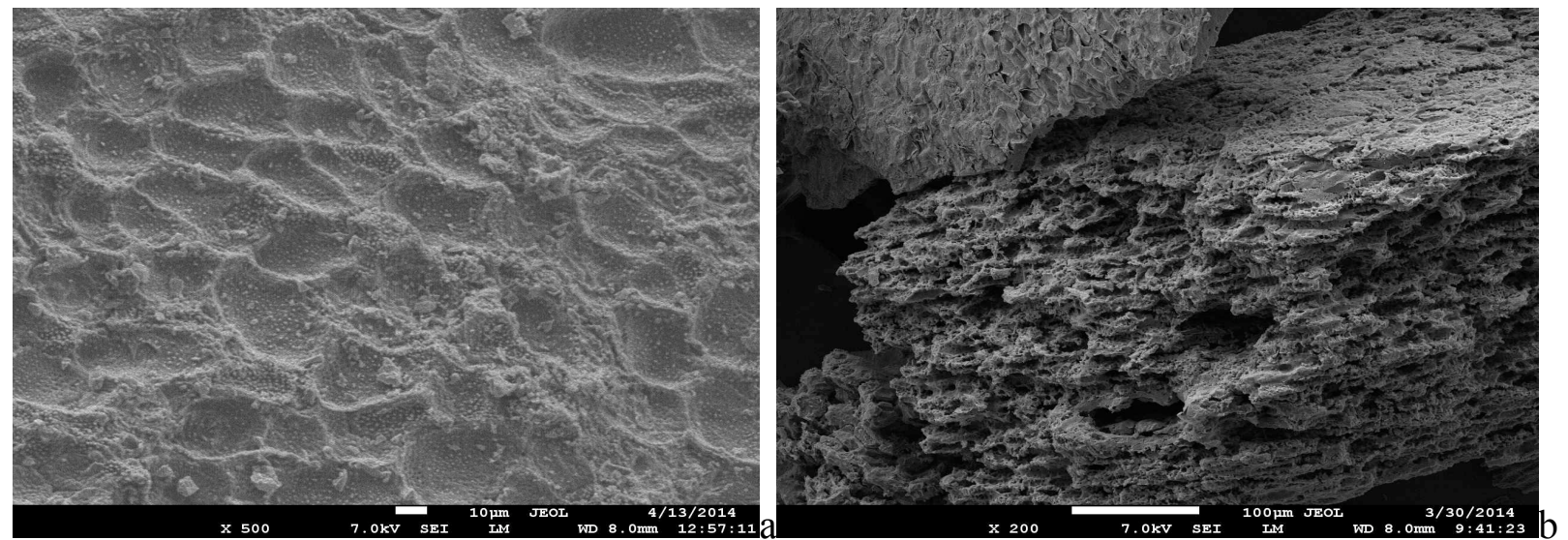

Figure 2. SEM images of RPS (a) and PHAC (b)

The SEM analysis of the RPS and PHAC were presented in Figure 2a-c. The surface morphology of the RPS showed no pores formation due to presence of volatiles and contaminants on its surface. However, there is development and widening of pores from the carbonized precursor to PHAC. This phenomena is more pronounced in PHAC as a result of the space created by loss of moisture, volatiles (hemicellulose, cellulose and lignin) and the chemical activant that remained in the cavities which is leached through washing with $0.1 \mathrm{M} \mathrm{HCl} \mathrm{[13].}$

FTIR

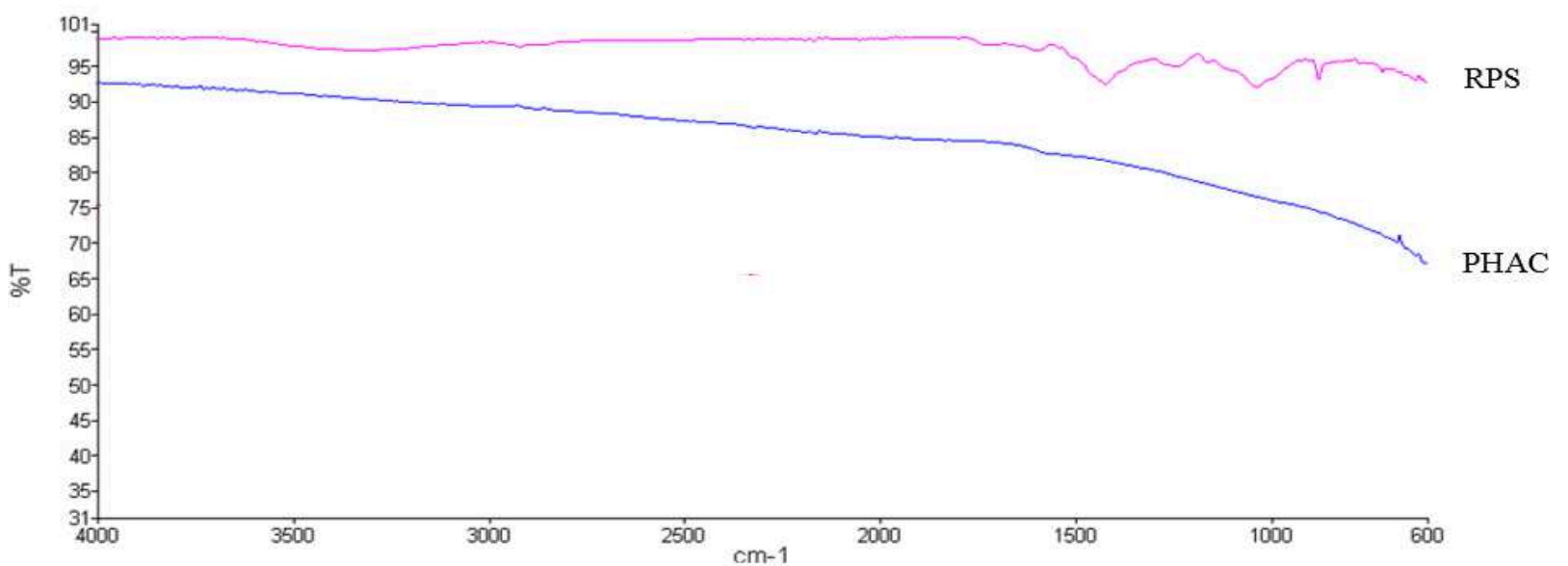

Figure 3. FTIR spectra of RPS and PHAC

The spectra of the raw precursor (RPS) as in Figure 3, shows the bands at $621 \mathrm{~cm}^{-1}, 875$, 1033, 1594 and $3330 \mathrm{~cm}^{-1}$ that corresponds to out of plane bending in benzene derivatives, C-O-C stretching vibration (in ester, ether and phenol), $\mathrm{C}-\mathrm{O}$ stretching in ethers, $\mathrm{C}=\mathrm{C}$ stretching in in aromatic rings and $\mathrm{OH}$ stretching vibration in $\mathrm{OH}$ functional groups respectively. However, the FTIR spectra of PHAC indicate elimination of some peaks at $\left(875,1594\right.$ and $\left.3330 \mathrm{~cm}^{-1}\right)$ as result of decomposition of functional groups and release of volatiles through carbonization process. Also, peaks at 620 and $3882 \mathrm{~cm}^{-1}$ were introduced, which corresponds to $\mathrm{OH}$ stretching vibration (in free alcohols and phenols) and bending vibration from carbon (triple bond) or C-H bond from alkynes [2]. 


\section{Conclusion}

The activated carbon prepared from palm oil shell by chemical activation with $\mathrm{KOH}$ attained a maximum of $410.7 \mathrm{~m}^{2} / \mathrm{g}, 350 \mathrm{~m}^{2} / \mathrm{g}$ and $0.2 \mathrm{~cm}^{3} / \mathrm{g}$ as Langmuir surface area, BET surface area and pore volume at carbonization temperature of $800^{\circ} \mathrm{C}$ with activation time of $2 \mathrm{~h}$ and impregnation ratio of 1:2. The increase in carbonization temperature decreases the surface area while increase in impregnation ratio increase it. The activation process and type of activant employed allows for accurately controlling the pore size distribution of the prepared carbon. Moreover, the process leads to synthesis of adsorbent material with suitable properties for a specific contaminant removal in water and wastewater.

\section{Acknowledgment}

The authors would like to acknowledge their appreciation to the office for research, innovation, commercialization and consultancy (ORICC) of University Tun Hussein Onn Malaysia for the graduate researcher incentive grant (GIPS) given to Abdurrahman Garba with VOT number 1253.

\section{References}

[1] H. L. Chong, P. S. Chia, and M. N. Ahmad, "The adsorption of heavy metal by Bornean oil palm shell and its potential application as constructed wetland media," Bioresour Technol, vol. 130, pp. 181-6, Feb 2013.

[2] N. S. Nasri, M. Jibril, M. A. A. Zaini, R. Mohsin, H. U. Dadum, and A. M. Musa, "Synthesis and Characterization of Green Porous Carbons with Large Surface Area by Two Step Chemical Activation with KOH," Jurnal Teknologi, vol. 67, 2014.

[3] B. Evbuomwan, A. Agbede, and M. Atuka, "A Comparative Study of the Physico-Chemical Properties of Activated Carbon from Oil Palm Waste (Kernel Shell and Fibre)."

[4] D. Adinata, W. M. Wan Daud, and M. K. Aroua, "Preparation and characterization of activated carbon from palm shell by chemical activation with K2CO3," Bioresour Technol, vol. 98, pp. 145-9, Jan 2007.

[5] I. Ali, M. Asim, and T. A. Khan, "Low cost adsorbents for the removal of organic pollutants from wastewater," J Environ Manage, vol. 113, pp. 170-83, Dec 302012.

[6] H. Asghar, S. Hussain, H. Sattar, E. Roberts, and N. Brown, "Improved phenol adsorption from aqueous solution using electrically conducting adsorbents," Korean Journal of Chemical Engineering, pp. 1-7, 2014/03/14 2014.

[7] H. Deng, G. Li, H. Yang, J. Tang, and J. Tang, "Preparation of activated carbons from cotton stalk by microwave assisted $\mathrm{KOH}$ and $\mathrm{K} 2 \mathrm{CO} 3$ activation," Chemical Engineering Journal, vol. 163, pp. 373-381, 2010.

[8] H. Demiral, İ. Demiral, B. Karabacakoğlu, and F. Tümsek, "Production of activated carbon from olive bagasse by physical activation," Chemical Engineering Research and Design, vol. 89, pp. 206-213, 2011.

[9] W. M. A. W. Daud and W. S. W. Ali, "Comparison on pore development of activated carbon produced from palm shell and coconut shell," Bioresource Technology, vol. 93, pp. 63-69, 5// 2004.

[10] J. i. Hayashi, T. Horikawa, I. Takeda, K. Muroyama, and F. Nasir Ani, "Preparing activated carbon from various nutshells by chemical activation with $\mathrm{K}<\mathrm{sub}>2</$ sub $>\mathrm{CO}<\mathrm{sub}>$ 3</sub>," Carbon, vol. 40, pp. 2381-2386, 2002. 
[11] Z. Khan, S. Yusup, M. M. Ahmad, and B. L. F. Chin, "Hydrogen production from palm kernel shell via integrated catalytic adsorption (ICA) steam gasification," Energy Conversion and Management, 2014.

[12] Y. S. Koay, I. S. Ahamad, M. M. Nourouzi, L. C. Abdullah, and T. Shean Yaw Choong, "Development of Novel Low-Cost Quaternized Adsorbent from Palm Oil Agriculture Waste for Reactive Dye Removal," BioResources, vol. 9, 2014.

[13] F.-c. Wu, R.-L. Tseng, and C.-C. Hu, "Comparisons of pore properties and adsorption performance of $\mathrm{KOH}$-activated and steam-activated carbons," Microporous and Mesoporous Materials, vol. 80, pp. 95-106, 2005. 